\title{
Echinococcus multilocularis and
} community on the eastern Tibetan Plateau: host species composition, molecular prevalence, and epidemiological implications

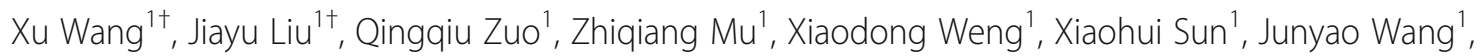
Belgees Boufana' ${ }^{2}$, Philip S. Craig ${ }^{3}$, Patrick Giraudoux ${ }^{4}$, Francis Raoul ${ }^{4}$ and Zhenghuan Wang ${ }^{1 *}$

\begin{abstract}
Background: The eastern part of the Tibetan Plateau is now recognized as an endemic region with the highest reported human infection rates in the world of human alveolar echinococcosis (AE) caused by Echinococcus multilocularis. Existing epidemiological studies on AE have mainly focused on the synanthropic environment, while basic parasitological and ecological aspects in wildlife host species remain largely unknown, especially for small mammal hosts. Therefore, we examined small mammal host species composition, occurrence, and the prevalence of both E. multilocularis and E. shiquicus in Shiqu County (Sichuan Province, China), eastern Tibetan Plateau.

Results: In total, 346 small mammals from five rodent and one pika species were trapped from four randomly set 0 . 25 ha square plots. Two vole species, Lasiopodomys fuscus $(n=144)$ and Microtus limnophilus $(n=44)$, and the plateau pika (Ochotona curzoniae) $(n=135)$, were the three most-dominant species trapped. Although protoscoleces of E. multilocularis and E. shiquicus were only observed in L. fuscus and O. curzoniae, respectively, cox1 and nad 1 gene DNA of E. shiquicus was detected in all the small mammal species except for Neodon irene, whereas E. multilocularis was detected in the three most-dominant species. The overall molecular prevalence of Echinococcus species was 5.8 (95\% Cl: 3.3-8.2\%) 10.7\% (95\% Cl: 7.4-14.0\%) (the conservative prevalence to the maximum prevalence with $95 \% \mathrm{Cl}$ in parentheses), whereas for E. multilocularis it was 4.3 (95\% Cl: 2.2-6.5\%) 6.7\% (95\% Cl: 4. 0-9.3\%), and 1.5 (95\% Cl: 0.2-2.7\%) 4.1\% (95\% Cl: 2.0-6.1\%) for E. shiquicus. The prevalence of both $E$.

multilocularis and E. shiquicus, was significantly higher in rodents (mainly voles) than in pikas. Phylogenetic analyses revealed that Echinococcus haplotypes of cox 1 from small mammal hosts were actively involved in the sylvatic and anthropogenic transmission cycles of E. multilocularis in the eastern Tibetan Plateau.

(Continued on next page)
\end{abstract}

\footnotetext{
* Correspondence: zhwang@bio.ecnu.edu.cn

${ }^{\dagger}$ Equal contributors

'School of Life Sciences, East China Normal University, Shanghai, China

Full list of author information is available at the end of the article
}

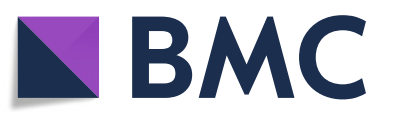

(c) The Author(s). 2018 Open Access This article is distributed under the terms of the Creative Commons Attribution 4.0 International License (http://creativecommons.org/licenses/by/4.0/), which permits unrestricted use, distribution, and reproduction in any medium, provided you give appropriate credit to the original author(s) and the source, provide a link to the Creative Commons license, and indicate if changes were made. The Creative Commons Public Domain Dedication waiver (http://creativecommons.org/publicdomain/zero/1.0/) applies to the data made available in this article, unless otherwise stated. 
(Continued from previous page)

Conclusions: In contrast to previous studies, the current results indicated that rodent species, rather than pikas, are probably more important natural intermediate hosts of E. multilocularis and E. shiquicus in the eastern Tibetan Plateau. Thus, understanding interspecific dynamics between rodents and pikas is essential to studies of the echinococcosis transmission mechanism and human echinococcosis prevention in local communities.

Keywords: Echinococcus multilocularis, E. shiquicus, Small mammal, Prevalence, Tibetan Plateau

\section{Background}

Echinococcosis, caused by Echinococcus spp. tapeworms, is a severe zoonosis with a worldwide distribution. Among the ten recognized species [1], Echinococcus granulosus (sensu stricto) and E. multilocularis are the two most widely distributed species, causing human cystic echinococcosis (CE) and alveolar echinococcosis (AE), respectively [2]. Both $\mathrm{CE}$ and $\mathrm{AE}$ are significant public health problems in the pasture areas of China [3], especially $\mathrm{AE}$ on the eastern Tibetan Plateau, which is the most pathogenic form of echinococcosis, and lethal in the absence of treatment; $91 \%$ of new cases annually worldwide occurred in China [4]. The eastern part of the Tibetan Plateau is now recognized as an endemic region with the highest reported human infection rates in the world $[5,6]$. Thus, echinococcosis has been listed as a critical endemic disease, and patients are eligible for free treatment from the national medical system in China [7].

As a typical example of the endemicity of Echinococcus spp. in the eastern Tibetan Plateau, the highest human echinococcosis infection rate in the world $(12.9 \%)$ was detected in Shiqu County, Sichuan Province [5]. Three Echinococcus species, E. granulosus (s.s.), E. multilocularis, and E. shiquicus, coexist in this region $[5,6,8,9]$. Echinococcus granulosus (s.s.) was confirmed to be mainly transmitting among synanthropic hosts, such as dogs and livestock, while transmission patterns of $E$. multilocularis and $E$. shiquicus involve complex sylvatic cycles that include several wildlife species [3]. The sylvatic transmission cycle of E. multilocularis in this area comprises the main definitive host species, Vulpes ferrilata (the Tibetan fox), and several intermediate host small mammals species (rodents and lagomorphs) $[8,10]$. By preying on small wild mammals, dogs bring the parasite into a synanthropic transmission ecosystem [3, 11]. Echinococcus shiquicus was originally thought to be transmitted only between $V$. ferrilata and Ochotona curzoniae (the plateau pika) [12]. However, although no human cases have yet been reported, dogs were found to have E. shiquicus DNA in their feces, and a role for dogs in the transmission of $E$. shiquicus is unknown [13].

Nevertheless, existing epidemiological studies have mainly focused on human communities and their domestic animals (e.g. dogs). Parasitological and ecological studies on how echinococcosis is transmitted and maintained in wildlife host species are rare [3, 10, 14]. For example, ecological and parasitological information about $E$. multilocularis in $V$. ferrilata is lacking (but see [15]). The prey species of $V$. ferrilata comprise several small mammal intermediate host species, mainly $O$. curzoniae and vole species [16]. Reports of E. multilocularis prevalence in intermediate host species on the eastern Tibetan Plateau have mainly focused on O. curzoniae and Lasiopodomys fuscus (the Smokey vole) [8, 17, 18]. However, other small mammals such as Phaiomys leucurus (the Blyth's mountain vole), Microtus limnophilus (the lacustrine vole), Neodon irene (the Irene's mountain vole), and Cricetulus kamensis (the Kam dwarf hamster) can also be abundant locally and could contribute to transmission [19]. He et al. [20] and Zhao [21] reported infection rates of $E$. multilocularis in small mammal communities of western Sichuan and southern Qinghai Provinces, respectively, but without clear reports of sampling design and species identification, evaluation of the relative importance of each small mammal host species in transmission is difficult. The need to prevent and control echinococcosis in local communities on pastures on the Tibetan Plateau requires improved understanding of the transmission ecology of Echinococcus spp. in their wildlife reservoir hosts. In particular, there is a crucial need to understand the composition of small mammal host species and the prevalence of $E$. multilocularis and E. shiquicus in this region.

Therefore, we studied the occurrence and prevalence of E. multilocularis and E. shiquicus in the small mammal community in Shiqu County on the eastern Tibetan Plateau. The genetic diversity of Echinococcus isolates recovered from this region was analyzed. Based on our results, we discuss the potential contribution of each host species during the transmission of echinococcosis in the local area.

\section{Methods \\ Study area}

Field studies were conducted at Yunbo Gou $\left(33^{\circ} 11^{\prime} \mathrm{N}\right.$, 97 $39^{\prime} \mathrm{E}$ ) in northwestern Shiqu County (Ganze Tibetan Autonomous Prefecture, Sichuan Province, China) with an elevation of 4200-4700 m above sea level. Habitat vegetation is primary Kobresia meadow, with shrubs, mainly Potentilla fruticosa and Salix cupularis, from the middle to the summit of some hills. Wang et al. [22] 
classified the vegetation in this region into four categories: grassland; grassland and shrub; shrub; and disturbed areas. Grassland was the main vegetation type, covering $>90 \%$ of the study area [23]. The warm season extends from late June to mid-August, and is the suitable time for small mammal capturing.

\section{Sampling of small mammals}

Small mammals were collected between July and August 2014, during the annual wildlife plague (Yersinia pestis) surveillance, conducted by the Shiqu County Center for Disease Control (Shiqu CDC). Four $50 \times 50 \mathrm{~m}$ trapping plots were randomly set on grassland at Yunbo Gou. Small mammals in the plot were trapped using breakback traps (size: $12 \times 6.5 \mathrm{~cm}$ ) set at the entrance of their dens. In total, 400 traps were set in each trapping plot. The trapping period of each plot was set for $24 \mathrm{~h} \mathrm{(10:00}$ $h$ to $10: 00 \mathrm{~h}$ the next day).

Each small mammal was sexed and its body measured; the head was stored in a $50 \mathrm{ml}$ capped tube with $95 \%$ ethanol for further species identification in the laboratory. The bodies were then dissected, and any lesions of Echinococcus spp. in the thoracic and peritoneal cavities and organs were carefully checked. When a lesion was detected, a small portion was cut and checked under a microscope for presence of protoscoleces. To a typical Echinococcus lesion, protoscoleces can be checked out, while to those atypical lesions, ones that were either too small (e.g. with a diameter $<1 \mathrm{~mm}$ ) or calcified, protoscoleces could not be observed. Therefore, to further confirm the existence of Echinococcus spp., samples of each typical and atypical lesion and from livers of small mammals without visible lesions were stored separately in $2 \mathrm{ml}$ storage tubes in $95 \%$ ethanol and stored at $-20^{\circ}$ $\mathrm{C}$ for further PCR analysis.

\section{Small mammal species identification}

Small mammal species identification was based on pelt color patterns, body measurement data, and skullmandible morphological characteristics (e.g. of the molars) according to Luo et al. [24] and Smith \& Xie [25]. To further confirm our identification, the specimens were compared with small mammal species specimens of the museum of the Northwest Institute of Plateau Biology, Xining.

\section{DNA extraction and PCR}

DNA extraction from samples (i.e. lesion and tissue samples) was conducted using the MiniBEST Universal Genomic DNA Extraction Kit Ver.5.0 (TaKaRa) according to the manufacturer's instructions. To identify Echinococcus spp., we used four primer pairs to perform parallel PCR tests of each sample. A Taeniidae family universal primer pair CO1JP2 (F/COI and R/COI, Table 1) [26] was used to amplify a region of approximately $874 \mathrm{bp}$ in length of the mitochondrial cox 1 gene. Three species-specific nad1 gene primer pairs (ND1Eg, ND1Em and ND1Es) were used to detect E. granulosus (s.s.), E. multilocularis and E. shiquicus, respectively (Table 1) [27]. All PCRs were performed in $50 \mu \mathrm{l}$ volumes with $4 \mu$ lemplate DNA, $1 \mu \mathrm{l}$ of the primers $(10 \mu \mathrm{mol} / \mathrm{l}), 1 \mu \mathrm{l}$ of bovine serum albumin (BSA, TaKaRa, Dalian, China), and $25 \mu \mathrm{l}$ Premix Taq (Ex Taq Version 2.0 plus dye, TaKaRa), made up to $50 \mu \mathrm{l}$ with deionized $\mathrm{H}_{2} \mathrm{O}\left(\mathrm{dH}_{2} \mathrm{O}\right)$. PCR of CO1JP2 comprised 30 cycles of $30 \mathrm{~s}$ at $94{ }^{\circ} \mathrm{C}, 45 \mathrm{~s}$ at $52{ }^{\circ} \mathrm{C}, 90 \mathrm{~s}$ at $72{ }^{\circ} \mathrm{C}$, and a final extension step of $72{ }^{\circ} \mathrm{C}$ for $5 \mathrm{~min}$. Parameters of the PCRs for the three nad 1 speciesspecific primer pairs were: $94{ }^{\circ} \mathrm{C}$ for 5 min followed by 35 cycles of $94{ }^{\circ} \mathrm{C}$ for $30 \mathrm{~s}, 45 \mathrm{~s}$ at the annealing temperature of each primer pair (Table 1 ), $72{ }^{\circ} \mathrm{C}$ for 90 $\mathrm{s}$, and then $72{ }^{\circ} \mathrm{C}$ for $10 \mathrm{~min}$. All PCRs were run on a DNA thermal cycler (Bio-Rad, Hercules, CA, USA).

\section{Other samples for molecular analyses}

DNA of Echinococcus spp. from other host species involved in local transmission cycles was also used in this study. These samples included: three Echinococcus-positive Tibetan fox fecal samples previously used by Jiang et al. [15]; four positive domestic dog fecal samples infected by E. multilocularis previously used by Boufana et

Table 1 Primer sequences, lengths of PCR amplicons and annealing temperatures

\begin{tabular}{|c|c|c|c|c|c|c|c|}
\hline Primers & Original code & Species & Target genes & Primer sequences & $\begin{array}{l}\text { Amplicon } \\
\text { length (bp) }\end{array}$ & $\begin{array}{l}\text { Annealing } \\
\text { temperature }\left({ }^{\circ} \mathrm{C}\right)\end{array}$ & Reference \\
\hline \multirow[t]{2}{*}{ CO1JP2 } & COIF & Taeniidae gen. sp. & $\operatorname{cox} 1$ & TTGAATTGGCACGTTTGAATGC & 875 & 52 & [26] \\
\hline & COIR & & & GAACCTAACGACATAACATAATGA & & & \\
\hline \multirow[t]{2}{*}{ ND1Em } & EmF19/3 & E. multilocularis & nad1 & TAGTTGTTGATGAAGCTTGTTG & 207 & 53 & [27] \\
\hline & EmR6/1 & & & ATCAACCATGAAAACACATATACAAC & & & \\
\hline \multirow[t]{2}{*}{ ND1Es } & EsF50 & E. shiquicus & nad1 & TTATTCTCAGTCTCGTAAGGGTCCG & 442 & 60 & [27] \\
\hline & EsR73 & & & CAATAACCAACTACATCAATAATT & & & \\
\hline \multirow[t]{2}{*}{ ND1Eg } & Eg1F81 & E. granulosus & nad1 & GTITTGGCTGCCGCCAGAAC & 226 & 62 & [27] \\
\hline & Eg1R83 & & & $\begin{array}{l}\text { AATTAATGGAAATAATAACAAA } \\
\text { CTTAATCAACAAT }\end{array}$ & & & \\
\hline
\end{tabular}


al. [13]; and AE lesion samples from six human patients living in Shiqu County between 2002 and 2007 [28]. The pretreatment and copro-DNA extraction protocols of Tibetan fox and dog fecal samples followed Jiang et al. [15] and Boufana et al. [13], respectively. Treatment of the human $\mathrm{AE}$ samples followed the small mammal sample pretreatment and DNA extraction protocol as described above.

\section{PCR product cloning and sequencing}

PCR products were subjected to agarose gel electrophoresis and stained with ethidium bromide (EB); positive screening results indicated that the target gene fragments had been amplified. Positive amplicons were excised carefully from the gel and purified with the TIAN gel Midi Purification Kit (TIANGEN, Beijing, China). Purified products were cloned into the T-Vector pMD $19(\mathrm{TaKaRa})$ in strict accordance with product instructions and transformed into competent Escherichia coli cells. DNA sequencing was conducted by Shanghai Majorbio Bio-Pharm Technology Co. Ltd. The results were compared with the NCBI database. (http://www. ncbi.nlm.nih.gov/BLAST).

\section{Statistics}

Percentages of each trapped mammal species were calculated and a Chi-square test was used to test the sex bias among them. Plateau pikas and vole species were main species of trapped mammals. Therefore, the different distribution patterns between voles and pikas were also tested using a Chi-square test.

Given that PCRs with different primer pairs might have different results, the prevalence of the same Echinococcus spp. detected by different primers could be inconsistent. Therefore, all the visually identified (i.e. individuals with typical and atypical lesions) and Echinococcus DNA-detected individuals were analyzed using a Chi-square test for trends in proportions to determine if the detection of the same Echinococcus spp. by different primers (i.e. cox 1 and nad1) was significantly different. Meanwhile, we defined the conservative prevalence of Echinococcus spp. by the percentage of positive samples detected by both cox 1 and nad 1 primers, and the maximum prevalence by the percentage of positive samples detected using at least one of the two genes.

To study how body condition might influence the detection of echinococcosis, all the visually identified (i.e. individuals with typical and atypical lesions) and Echinococcus DNA-detected individuals were analyzed using logistic regression models with four variables: (i) relative body weight (RW): the body weight of each individual divided by the heaviest one of the same species collected in this study; (ii) relative head-body length (RHBL): the head-body length of each individual divided by the longest one of the same species collected in this study; (iii) cross effect of relative weight and head-body length (CWL), expressed using the product of (ii) and (iii) of each individual; and (iv) lesions: three types, (typical, atypical, and no obvious lesion). The generalized $R^{2}$ [29] and AICc [30] of each model were calculated. The model with the lowest AICc was selected as the best model, while models with $\triangle$ AICc $<2$ compared with the AICc of the best model were also selected.

The development of Echinococcus lesions is known to be positively related with age of the host [31-34]. Morris [35] recommended using the dry weight of eye lenses to evaluate age, as practiced by Burlet et al. $[34,36]$. We could not use this method because no scrutinized ageeye lens weight analyses of our studied species have ever been reported in China. Thus, we used weight and body length to indicate the relative age of each trapped individual [35]. Logically, it should be easier to identify Echinococcus infection in larger, heavier and older individuals [35]. Given that body size can differ significantly among species, relative measurements (i.e. RW and RHBL) of each individual were calculated by dividing the measurement with the data of the largest or heaviest individual of its own species collected in this study.

All statistical analyses were conducted using $\mathrm{R}$ 3.4.0 (http://www.r-project.org).

\section{Phylogenetic analyses}

To analyze the phylogenetic relationships between $E$. multilocularis collected from small mammal hosts and from other host species of both local and wider geographical transmission cycles, maximum likelihood trees (ML trees) and Bayesian inference trees based on cox1 gene fragment haplotypes were constructed. Haplotypes of $\operatorname{cox} 1$ sequences were acquired from this study and 18 E. multilocularis cox 1 sequences were selected from GenBank. One E. shiquicus (from one of the three Tibetan fox fecal samples, F12033) and one E. granulosus (s.s.) cox1 sequences (GenBank accession ID: KJ628374. 1) were used as outgroups (Additional file 1: Table S1). When selecting sequences online, only data from indigenous host species were used. We did not build trees based on E. multilocularis nad 1 gene sequences because the nad1 amplicons in E. multilocularis were too short (Table 1) and online data from different geographical regions were insufficient. Phylogenetic trees based on $E$. shiquicus sequences were not given in this study because only limited molecular data from this species from only a small area of the eastern Tibetan Plateau are available on GenBank, which would result in trees of E. shiquicus being less informative than trees of $E$. multilocularis.

Before construction of the phylogenetic trees, sequences were edited (Bioedit 7.0.9 [37]) and aligned (ClustalX2 [38]). Haplotypes were summarized, and 
Tajima's $D$ and Fu's $F s$ tests were conducted by DnaSP v. 5 [39]. Substitution saturation of the sequence matrix was tested by DAMBE 5 [40]. jModelTest v.2.1.4 [41] was used to test for the best-fit models of nucleotide substitution. Finally, ML trees were constructed using MEGA 7 by setting a 'GRT + I' substitution model with 1000 bootstrap replications. Bayesian trees were constructed using MrBayes 3.2.4 [42] by setting the 'TIM3 + I' substitution model, using Markov Chain Monte Carlo (MCMC) posterior probability estimation for 2,000,000generation with a 1000-generation sampling interval, and discarding the first $25 \%$ aging samples when summing up each tree. The best Bayesian tree was then compiled and processed by FigTree 1.4.3 (http://tree.bio. ed.ac.uk/software/figtree). Finally, a network diagram was drawn using Network 5.0 (http://www.fluxus-engineering.com).

\section{Results}

\section{Small mammal species composition}

A total of 346 small mammals were captured from the four trapping plots in the study site in July and August 2014. Except for one, Cricetulus longicaudatus (longtailed dwarf hamster), most small mammals trapped were pikas and voles: L. fuscus $41 \%$ (144/346); O. curzoniae 39\% (135/346); M. limnophilus 13\% (44/346); $P$. leucurus 5\% (16/346); and $N$. irene $2 \%(6 / 346)$. No significant sex bias was detected from the trapped small mammal species $\left(\chi^{2}=4.485, d f=5, P=0.482\right)$. Pikas were only trapped in the first and second plots, whereas voles were mainly trapped from the third and fourth plots (Table 2). There were significant differences in the distribution of pikas and voles among the four trapping plots $\left(\chi^{2}=267.660, d f=3, P<0.001\right)$.

\section{Prevalence of Echinococcus spp. in the small mammal community}

Suspected Echinococcus lesions were found in 62 individuals. Lesions in the lungs were found in five $O$. curzoniae and in both liver and lungs in another five $O$. curzoniae. All the other lesions of the remaining 52 individuals were in the liver. Molecular analyses later detected Echinococcus mtDNA in 22 out of the 62 individuals, including all the 5 individuals with typical lesions (i.e. E. multilocularis in 4 L. fuscus and E. shiquicus in 1 O. curzoniae), in which Echinococcus protoscoleces were checked out (Additional file 1: Table S2). Among these 22 individuals, E. multilocularis lesions in 20 voles (i.e. $15 \mathrm{~L}$. fuscus and $5 \mathrm{M}$. limnophilus) were in the liver, whereas in the two O. curzoniae, one had typical E. shiquicus lesions in both liver and lungs and the other one had atypical E. multilocularis lesions in the lungs. In other individuals without visible lesions, E. shiquicus mtDNA was detected in 13 individuals, while E. multilocularis was detected in 2 (see Additional file 1: Table S2 for details). Therefore, the overall maximum prevalence of Echinococcus in small mammals was 10.7\% (37/346, 95\% CI: 7.4-14.0\%), and the conservative prevalence was $5.8 \%$ (20/346, 95\% CI: 3.3-8.2\%). The maximum prevalence of E. multilocularis was $6.7 \%$ (23/346, 95\% CI: $4.0-9.3 \%)$ with a conservative prevalence of $4.3 \%$ (15/346, 95\% CI: 2 . 2-6.5\%), whereas the maximum prevalence of E. shiquicus was $4.1 \%$ (14/346, 95\% CI: $2.0-6.1 \%)$ and the conservative prevalence was $1.5 \%$ (5/346, 95\% CI: 0.2-2.7\%) (Table 3). No E. granulosus (s.s.) infections were detected.

There was a significant difference between the use of cox 1 vs nad 1 in the detection of Echinococcus infection. For $E$. shiquicus, significantly more infections were detected using nad 1 primers than with $\operatorname{cox} 1\left(\chi^{2}=10.480\right.$, $d f=1, P=0.001)$, whereas the use of $\operatorname{cox} 1$ primers detected more E. multilocularis infections than with nad $1\left(\chi^{2}=7.415, d f=1, P=0.006\right)$.

There was a distinct pattern to the prevalence of $E$. multilocularis and E. shiquicus in each small mammal species. Cricetulus longicaudatus and P. leucurus were only detected with E. shiquicus DNA, whereas no Echinococcus infection was detected in $N$. irene (Table 4). For the three most-dominant small mammal host

Table 2 Statistics of species, gender, and anatomy of captured rodents

\begin{tabular}{|c|c|c|c|c|c|c|c|c|}
\hline \multirow[t]{2}{*}{ Species $(n)$} & \multicolumn{4}{|c|}{ No. captured in different quadrats $(n)$} & \multicolumn{3}{|c|}{$\operatorname{Sex}(n)$} & \multirow[t]{2}{*}{ Lesions $^{a}$} \\
\hline & No. 1 & No. 2 & No. 3 & No. 4 & Male & Female & Unknown & \\
\hline Cricetulus longicaudatus Long-tailed dwarf hamster $(n=1)$ & 1 & - & - & - & - & 1 & - & - \\
\hline Phaiomys leucurus Blyth's mountain vole $(n=16)$ & - & 2 & 7 & 7 & 9 & 7 & - & - \\
\hline Neodon irene Irene's mountain vole $(n=6)$ & - & - & 1 & 5 & 3 & 3 & - & - \\
\hline Microtus limnophilus Lacustrine vole $(n=44)$ & - & 9 & 20 & 15 & 18 & 26 & - & 6 \\
\hline Lasiopodomys fuscus Smokey vole $(n=144)$ & - & 14 & 43 & 87 & 74 & 68 & $2^{b}$ & $19(4)$ \\
\hline Ochotona curzoniae Plateau pika $(n=135)$ & 65 & 70 & - & - & 58 & 77 & - & $37(1)$ \\
\hline Total $(n=346)$ & 66 & 95 & 71 & 114 & 162 & 182 & 2 & 62 \\
\hline
\end{tabular}

Abbreviation: $n$ number of individuals

${ }^{a}$ The number of individuals with distinct pathological features/lesions (number of individuals with Echinococcus protoscoleces)

${ }^{\mathrm{b}}$ Carcasses were partly damaged by raptors 


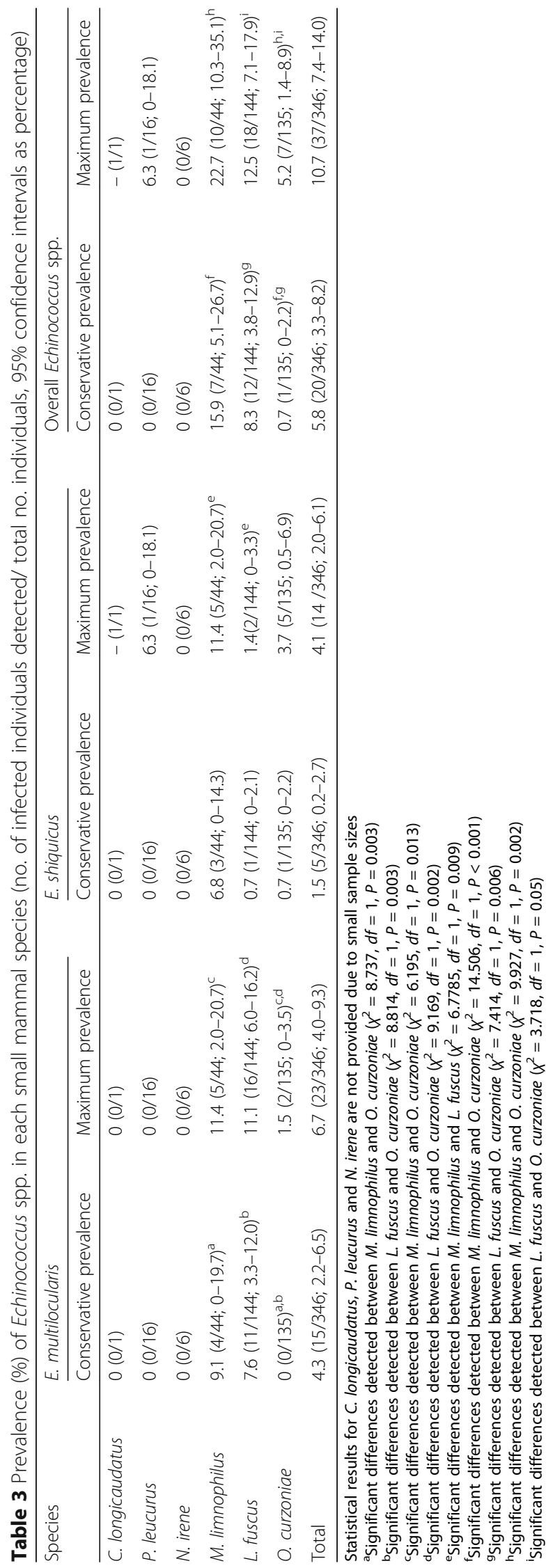


Table 4 Variables of host body condition influencing the general maximum prevalence of Echinococcus species as revealed by the best logistic regression model

\begin{tabular}{|c|c|c|c|c|c|c|}
\hline \multicolumn{4}{|c|}{ Log odds of significant variables \pm SE } & \multicolumn{3}{|c|}{ Model evaluation } \\
\hline \multirow{2}{*}{$\begin{array}{l}\text { Relative body } \\
\text { weight }\end{array}$} & \multirow{2}{*}{$\begin{array}{l}\text { Relative head- } \\
\text { body length }\end{array}$} & \multicolumn{2}{|l|}{ Lesions $^{a}$} & \multicolumn{2}{|l|}{$\mathrm{AICC}$} & \multirow{2}{*}{$\begin{array}{l}\text { Generalized } R^{2} \text { o } \\
\text { the best model }\end{array}$} \\
\hline & & 1 vs 0 & 2 vs 0 & Best model & Null model & \\
\hline$-16.010 \pm 4.558$ & $19.134 \pm 8.521$ & -21.982 & -0.556 & 49.677 & 108.473 & 0.572 \\
\hline
\end{tabular}

${ }^{\mathrm{a}}$ Categorical data, no SE presented

Abbreviations: 0, individuals without visible lesions; 1 , individuals with atypical lesions; 2 , individuals with typical lesions; SE standard error

species (L. fuscus, O. curzoniae and M. limnophilus), both $E$. multilocularis and E. shiquicus were detected. There were no mixed Echinococcus spp. infections or DNA detected in a single host individual (Table 3). Among the three most-dominant host species, the prevalence of E. multilocularis and E. shiquicus were significantly higher in M. limnophilus, whereas the prevalence of these two Echinococcus spp. in O. curzoniae was significantly lower. Lasiopodomys fuscus had an intermediate Echinococcus prevalence (Table 3). The maximum prevalence of $E$. multilocularis and the overall Echinococcus prevalence in L. fuscus were significantly higher than in O. curzoniae (Table 3). No significant prevalence bias was detected between male and female mammals, except for M. limnophilus, in which the maximum prevalence of Echinococcus was significantly higher in females than in males (detected individuals, female/male, $\left.9 / 1 ; \chi^{2}=4.189, d f=1, P=0.041\right)$.

Regression model simulation revealed that Echinococcus infection was detected in individual hosts with significantly longer RHBL (log odds ratio, 19.134), while their RBWs were significantly lighter than those without infection (log odds, -16.010) (Table 4). Moreover, although typical lesions were useful signs of infection (with a log odds ratio of -0 . 556 relative to the molecular results), atypical lesions were misleading and caused significantly more misidentification of infections ( $\log$ odds ratio of -21.982 , Table 4).

\section{Phylogenetic relationships between E. multilocularis cox 1 gene haplotypes}

In total, 45 haplotypes of a 768 bp long E. multilocularis cox 1 gene fragment were acquired from 23 small mammals (76 sequences), six human AEs (6 sequences), four dog feces (4 sequences), and two Tibetan fox fecal samples (5 sequences) in this study, with an additional 17 sequences from online sources. Among the 76 sequences from Shiqu County, 33 haplotypes of E. multilocularis (i.e. Hap06-Hap38) were confirmed (Additional file 1: Table S1), of which Hap06 was the dominant haplotype, with 58 sequences covering all the human AE, dog, and Tibetan fox fecal samples, and 21 small mammal samples from L. fuscus, M. limnophilus and O. curzoniae (Fig. 1, Additional file 1: Table S1). The haplotype and

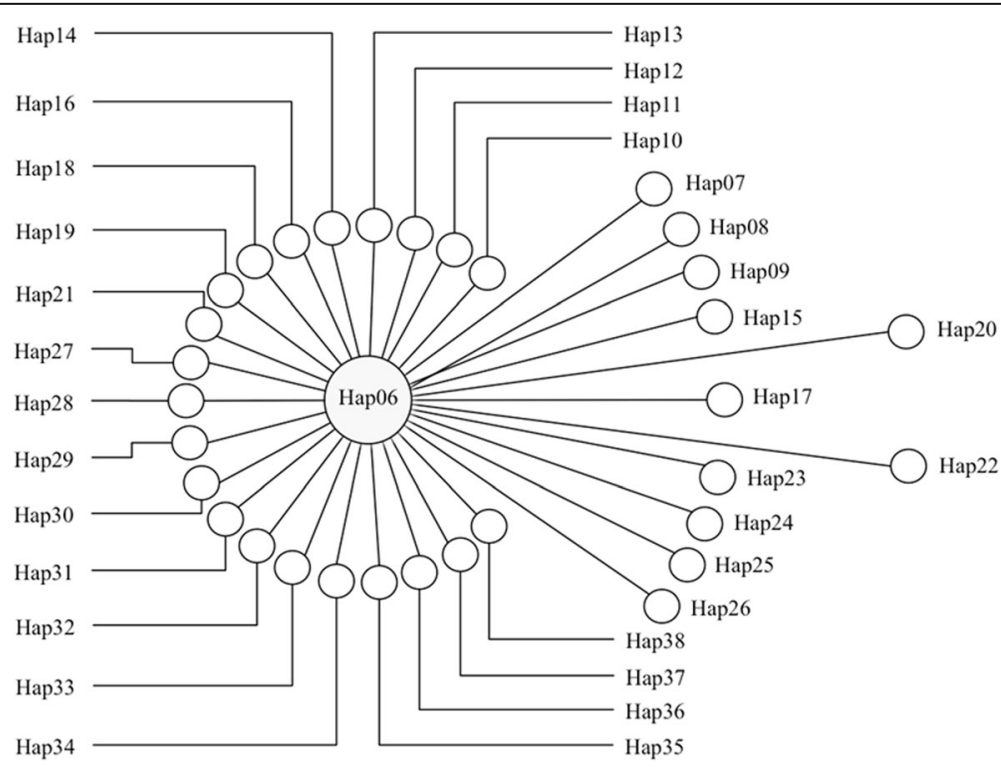

Fig. 1 Network of 33 Echinococcus multilocularis cox 1 gene haplotypes collected from samples in this study. The size of the circle represents the number of species of hosts with the E. multilocularis gene haplotype (Hap06 isolated from six species including humans, dogs, Tibetan foxes, two species of voles and plateau pikas, while each of the other haplotypes has only one host species, see Additional file 1: Table S1 for details). The distance between the circle centers shows the variation between two haplotypes (i.e. 1 bp mutation between Hap06 and Hap36) 
nucleotide diversities for the $E$. multilocularis cox 1 gene from the small mammal community in this study were $0.655 \pm 0$. 064 and $0.0014 \pm 0.0002$, respectively. Significant negative values in both Tajima's $D(D=-2.83311, P<0.001)$ and Fu's $F s(F s=-46.942, P<0.001)$ tests indicated that the $E$. multilocularis population in the small mammal community of Shiqu County is currently expanding, and the dominant Hap06 haplotype may be under strong purifying selection.

Both ML and Bayesian trees were constructed based on 56 sequences, including $54 \mathrm{E}$. multilocularis sequences and two E. granulosus (s.s.) and E. shiquicus sequences as outgroups (Additional file 1: Table S1). Both trees demonstrated identical topological relationships between haplotypes, but only the Bayesian tree is included here (Fig. 2) because of its more concise structure. The Tibetan Plateau cluster was distinctive from other geographical regions of the world, and mainly comprised the Shiqu haplotypes Hap06-Hap38, the Qinghai Province haplotype Hap05 (also from the Tibetan Plateau), and two other sequences (Hap04 and Hap06-Vole-NO.RUS, Additional file 1: Table S1) from neighboring geographical regions (Fig. 2).

\section{Discussion}

Transmission of E. multilocularis and E. shiquicus relies on small mammal species as intermediate hosts [3].

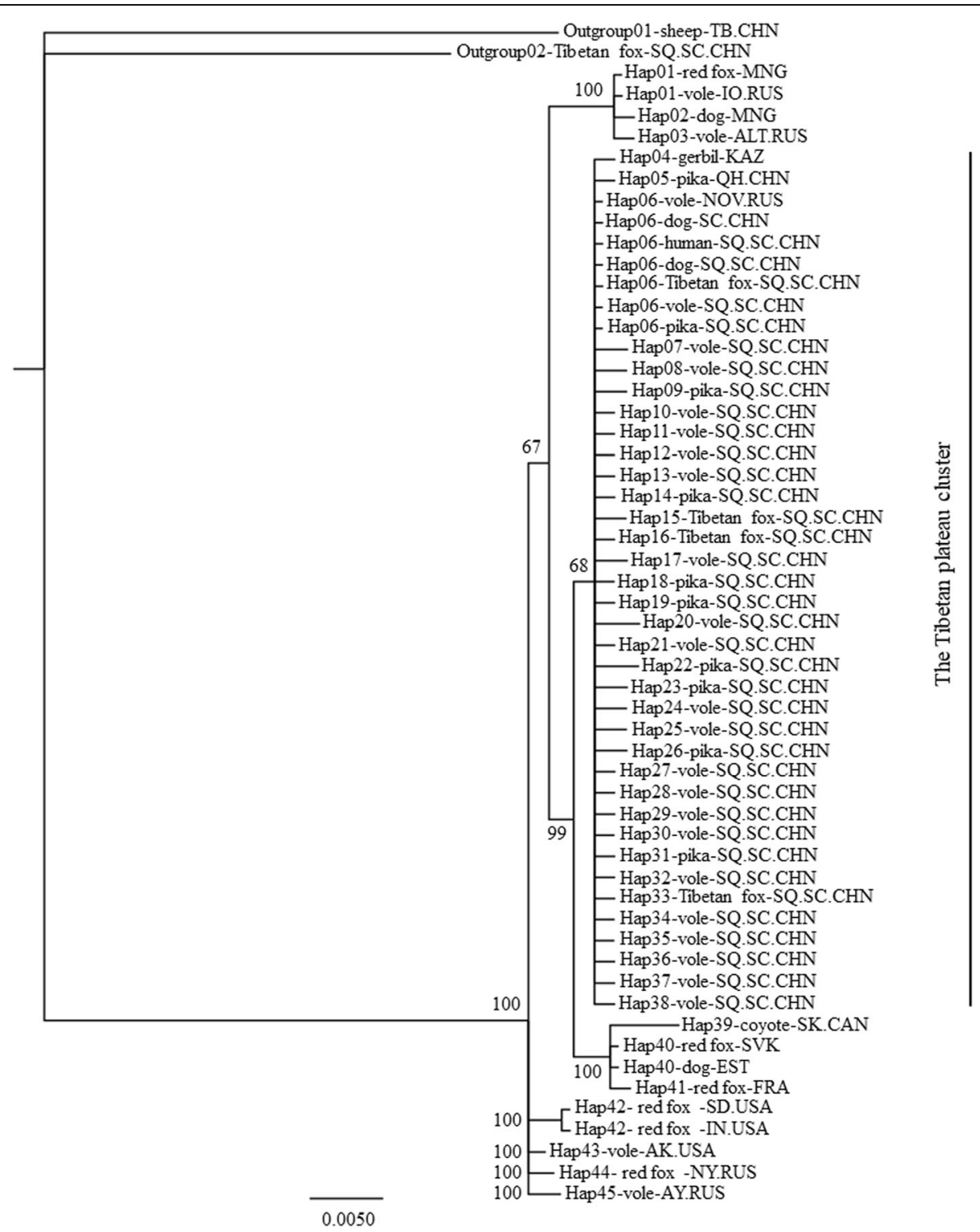

Fig. 2 Phylogenetic tree comparing the geographical distribution between mtDNA cox1 gene haplotypes of Echinococcus multilocularis. The Bayesian phylogenetic analysis was used by setting the "TIM3+I" substitution model, 2,000,000-generation MCMC posterior probability estimation with a 1000-generation sampling interval, and discarding the first $25 \%$ samples when summing up trees 
Although monographs of the comprehensive taxonomy of small mammal species with coarse resolution distribution maps have been published [25, 43, 44], small mammal assemblages in western China still pose great challenges. Knowledge of the distribution, ecology, and even the basic taxonomy of these small mammals, especially rodent species, is lacking. Consequently, epidemiological research focused on small mammal host species based on basic taxonomic and ecological methodologies in specific E. multilocularis-endemic areas of China is limited $[8,10,14]$. Thus, our understanding of the transmission ecology of echinococcosis in the Tibetan Plateau ecosystem is far from complete.

\section{Small mammal host species community composition}

Although all the six small mammal species reported in this study have been recorded previously on the Tibetan Plateau, information about small rodent species such as arvicolids and cricetids was largely lacking from Shiqu before the 21st century $[45,46]$. He et al. [20] reported alveolar echinococcosis in the lagomorphs Ochotona curzoniae and Lepus oiostolus, and also in the commensal rodents $N$. irene, and Mus musculus in Shiqu. Raoul et al. [19] studied the habitat ecology of small mammal communities in Shiqu, reporting for the first time P. leucurus and C. kamensis in Sichuan Province. However, neither of these two studies reported L. fuscus in Shiqu. The distribution area of L. fuscus was judged to be restricted to southern Qinghai Province, and this was not considered to be a species distributed to $\mathrm{Si}$ chuan $[24,25,43,45]$. However, in local plague surveillance studies $[47,48]$ and pest control schemes $[49,50]$, L. fuscus was judged to be a dominant rodent species in the high plateau pasture areas of northwest Sichuan. Lasiopodomys fuscus is morphologically similar to other vole species, such as P. leucurus, and thus could be included in reports in error if an accurate morphological identification is lacking [51]. Shiqu is located at the northwestern point of Sichuan Province, on the southern border of Qinghai; therefore, it is possible that what is thought to be the southern limit of the range of L. fuscus is incorrect [46]. The current study confirmed the presence of L. fuscus in Shiqu County, where it was the most abundant species of the five trapped rodent species and is likely to have a larger population than that of $O$. curzoniae in this region (Table 2).

\section{Importance of rodent species in the transmission of echinococcosis}

Although the potential importance of rodent species as intermediate hosts of $E$. multilocularis on the eastern Tibetan Plateau has been mentioned previously elsewhere $[10,14,51,52]$, O. curzoniae were the most frequently examined small mammal host species with large sample sizes $[8,17,18,20,21,52-54]$. For example, when evaluating the prevalence of E. multilocularis, Zhao [21] reported a prevalence of $15.2 \%$ in O. curzoniae (34/224) and $20 \%$ in L. fuscus (1/5 individuals). Similarly, Zhang \& Wang [18] reported a prevalence of $5.3 \%$ in O. curzoniae (62/1177), but only $0.4 \%$ in $L$. fuscus $(1 / 269)$. Thus, much smaller sampling sizes might be an important reason for the reported low prevalence of E. multilocularis in rodent species. In terms of E. shiquicus, O. curzoniae was previously the only confirmed intermediate host species [12, 54]. By contrast, our data revealed that, among the three most-abundant small mammal species, both M. limnophilus and L. fuscus had a significantly higher molecular prevalence of E. multilocularis and $E$. shiquicus than did O. curzoniae (Table 3). Moreover, E. shiquicus DNA was detected not only in the three mostabundant small mammal species, but also in the other two rodent species sampled (P. leucurus and $C$. longicaudatus) (Table 3). Although trapping data might not reflect the exact abundance of each species, the higher molecular prevalence of both E. multilocularis and $E$. shiquicus (Table 2) in rodents than in pikas suggests that rodent species are probably more important intermediate host species than pikas during the transmission of both E. multilocularis and E. shiquicus.

Traditionally, epidemiological studies of echinococcosis in western China mainly focused on human and domestic animal populations because of their obvious direct interactions especially regarding transmission of human $\mathrm{CE}$ and a role for dogs in risk of human $\mathrm{AE}$. Phylogenetic analyses revealed that all $33 \operatorname{cox} 1$ gene haplotypes from Shiqu County were closely related (Fig. 1), and clustered with haplotypes from other studies to form the Tibetan Plateau group, which is distinct from haplotypes from other geographical regions (Fig. 2). Hap06 was the dominant haplotype of E. multilocularis discovered in humans, domestic dogs, and almost all the wildlife host species tested in this study, including the three most dominant small mammal species (i.e. O. curzoniae, M .limnophilus and L. fuscus) (Fig. 2, Additional file 1: Table S1). These results confirm that small mammal species and dogs together comprise a wildlife and peri-domestic ecosystem for transmission of $E$. multilocularis. Thus, understanding the epidemiology in wildlife host species is pivotal to understanding the life-cycles and transmission ecology of these parasites.

For a parasite species such as E. multilocularis, which can utilize multiple host species, understanding the interspecific dynamics between host species is essential for understanding its transmission [55]. Both Tajima's $D$ and Fu's $F s$ tests revealed the population expansion of $E$. multilocularis in the small mammal community in the study region, as supported by Nakao et al. [28]. Could this expansion be the result of the frequently reported 
increases in small mammal populations and their interspecific dynamics in western China? Ochotona curzoniae and several vole species are the main prey of the Tibetan fox ( $V$. ferrilata) on grasslands of the eastern Tibetan Plateau [16]. The significant differences in prevalence of E. multilocularis among voles and O. curzoniae (Table 3) suggest that interspecific dynamics among these small mammal species could be essential factors influencing the predator-prey food chain, which would affect the epidemiology of E. multilocularis across all pasture areas on the Tibetan Plateau. For example, Wang et al. [56] reported a high density of both O. curzoniae and voles in open grassland areas within $2 \mathrm{~km}$ of villages. Ochotona curzoniae is usually blamed for degrading the grassland ecosystem of the eastern Tibetan Plateau and, consequently, has been a main target for poisoning to protect the grasslands [49, 50, 57]. Areas around villages are usually where poisoning programs are located. The fact that there was a significantly higher prevalence of $E$. multilocularis in vole species compared with $O$. curzoniae (Table 3) suggests that pika may have a lesser role compared to voles in the transmission of E. multilocularis. Furthermore the deliberate poisoning of O. curzoniae could result in increased densities of vole species, accompanied by a higher prevalence of E. multilocularis in wildlife, dogs and humans in local areas.

\section{Small mammal body condition and detection of Echinococcus DNA}

The regression model revealed that individuals with larger RHBL were more likely to be detected with Echinococcus, based on the molecular tests (Table 4). Linear body dimensions are more or less correlated with age, especially in animals with short lifespans [35]. Thus, the results of the current study showed that older small mammals were more likely to have E. multilocularis or E. shiquicus infections. Similarly, Burlet et al. [34] reported that older Arvicola terrestris had a higher prevalence of $E$. multilocularis than younger animals. In small mammal hosts, E. multilocularis requires several months to grow from an oncosphere to a fertile metacestode [58]. Consequently, the development of metacestode lesions can be synchronized with the aging process of its hosts, such as rodents and pikas, further confirming the importance of understanding the host population structure and dynamics when evaluating the present infection burden and predicting the future trend of a specific parasitic species.

Although typical lesions were indicative of infection with specific Echinococcus species, as revealed by the regression model (Table 4), they were harder to find than were the frequently detected atypical lesions (Additional file 1: Table S2). However, low values of atypical lesions for determining Echinococcus infection (Table 4, Additional file 1: Table S2) required the use of molecular analyses. Nevertheless, such analyses provide the molecular-positive rate of the parasite, which is not equivalent to its true prevalence. For example, E. shiquicus DNA was detected in several rodent species; however, if no typical lesions with metacestodes were observed (Additional file 1: Table S2), then it was not possible to conclude that there was an established parasitic infection. Thus, the function of rodent species as natural intermediate hosts of $E$. shiquicus still requires further study. Moreover, many primers have been designed to test various nuclear $[59,60]$ and mitochondrial $[15,26,27,61]$ genes of Echinococcus species. In this study, the cox 1 and nad1 genes were used. However, the significantly inconsistent results achieved with both genes (Additional file 1: Table S2) suggested that multiple parasite genes should be tested in the same epidemiological study. In addition, a prevalence interval that is based on the different levels of detection as determined by the available genes (e.g. the maximum and conservative prevalence defined in this study) would be more objective than using a single prevalence.

\section{Conclusions}

Our observations suggest that rodent (vole) species are probably more important natural intermediate hosts of both E. multilocularis and E. shiquicus in Shiqu County on the eastern Tibetan Plateau. In addition to O. curzoniae, the small mammal community sustains echinococcosis transmission in the Tibetan ecosystem. Moreover, small mammal communities usually have complex intraand interspecific relationships, which influence the population and spatial dynamics of each host species and, thus, the transmission patterns of alveolar echinococcosis and E. shiquicus in local areas. Consequently, we recommend that future studies on the epidemiology of human AE must consider the basic transmission ecology of the small mammal community as an essential component of research and for control purposes.

\section{Additional file}

Additional file 1: Table S1. Information for $\operatorname{cox} 1$ sequences used in the Bayesian phylogenic tree in this study. Table S2. Echinococcus detection results of each suspected small mammal sample based on necropsy and molecular analyses. (DOCX $35 \mathrm{~kb}$ )

\section{Abbreviations}

AE: alveolar echinococcosis; CDC: center for disease control; CE: cystic echinococcosis; CWL: cross effect of relative weight and head-body length; EB: ethidium bromide; ML: tree maximum likelihood tree; RHBL: relative head-body length; RW: relative body weight; s.s. : sensu stricto

\section{Acknowledgements}

We thank Qiu Jiamin, Chen Xingwang, and other colleagues (Sichuan Center of Disease Control, Chengdu, China) for their help with field research.

Colleagues from the Shiqu County Center of Disease Control provided vital logistical support during the field study. We are grateful to reviewers for their invaluable comments to improve this manuscript. 


\section{Funding}

National Science Foundation of China (NSFC \#31071944 and \#31470488): supporting the study from the design, field trips and allowance for Chinese authors, data collection in field, laboratory analysis, and data analysis, writing and language polishing. The National Key Program of Research and Development Ministry Science and Technology of China (2016YFC0503200): supporting field trips for Chinese authors, writing, and publishing. NSF EID (US) program (\#TW001565) and the Wellcome Trust (\#094325/Z/10/Z): supporting trips, data collection in field, laboratory analysis of the European authors.

\section{Availability of data and materials}

All data generated or analyzed during this study are included in this published article and its Additional file 1.

\section{Authors' contributions}

XW: major writer of the manuscript, molecular analysis and data processing of the echinococcosis materials. JL: collecting echinococcosis materials in Shiqu, small mammal species identification and data processing. QZ, ZM and XW: molecular analysis of small mammal materials. XS and JW: small mammal species identification. BB: dog fecal and human AE sample processing and molecular data analysis. PSC, PG and FR: designing the study and contributing in the writing of the manuscript. ZW: main investigator of the study, designing the study, data analysis and writing the manuscript. All authors read and approved the final manuscript.

\section{Ethics approval and consent to participate}

The protocol used to collect the small mammals was approved by the East China Normal University Animal Care and Use Committee (identification number: Q20170501).

\section{Competing interests}

The authors declare that they have no competing interests

\section{Publisher's Note}

Springer Nature remains neutral with regard to jurisdictional claims in published maps and institutional affiliations.

\section{Author details}

${ }^{1}$ School of Life Sciences, East China Normal University, Shanghai, China. ${ }^{2}$ Department of Infectious, Parasitic and Immuno-Mediated Diseases, Istituto Superiore di Sanità, Rome, Italy. ${ }^{3}$ School of Environment and Life Sciences, University of Salford, Greater Manchester, UK. ${ }^{4}$ Chrono-Environment Lab, University of Bourgogne-Franche-Comté and CNRS, Besançon, France.

Received: 27 November 2017 Accepted: 25 April 2018

Published online: 16 May 2018

\section{References}

1. Nakao M, Lavikainen A, Yanagida T, Ito A. Phylogenetic systematics of the genus Echinococcus (Cestoda: Taeniidae). Int J Parasitol. 2013:43:1017-29.

2. Thompson RCA. The taxonomy, phylogeny and transmission of Echinococcus. Exp Parasitol. 2008;119:439-46.

3. Wang $Z H$, Wang XM, Liu XQ. Echinococcosis in China, a review of the epidemiology of Echinococcus spp. EcoHealth. 2008:5:115-26.

4. Torgerson PR, Keller K, Magnotta M, Ragland N. The global burden of alveolar echinococcosis. PLoS Negl Trop Dis. 2010;4:e722.

5. Li TY, Qiu JM, Yang W, Craig PS, Chen XW, Xiao N, et al. Echinococcosis in Tibetan populations, western Sichuan Province, China. Emegr Infect Dis. 2005;11:1866-73.

6. Li TY, Chen XW, Zhen R, Qiu JM, Qiu DC, Xiao N, et al. Widespread coendemicity of human cystic and alveolar echinococcosis on the eastern Tibetan Plateau, northwest Sichuan/southeast Qinghai, China. Acta Trop. 2010;113:248-56.

7. National Health and Family Planning Commission of the People's Republic of China. Echinococcosis prevention action plan (2010-2015). 2010. http:// www.gov.cn/zwgk/2010-12/14/content_1765485.htm. Accessed 1 Dec 2010.

8. Qiu JM, Chen XW, Ren M, Luo CX, Liu DL, Liu HT, et al. Epidemiological study on alveolar hydatid disease in Qinghai-Xizang plateau. J Pract Parasit Dis. 1995;3:106-9.
9. Xiao N, Qui JM, Nakao M, Li TY, Yang W, Chen XW, et al. Echinococcus shiquicus n. sp., a taeniid cestode from Tibetan fox and plateau pika in China. Int J Parasitol. 2005;35:693-701.

10. Giraudoux P, Pleydell D, Raoul F, Quéré J-P, Wang Q, Yang YR, et al. Transmission ecology of Echinococcus multilocularis: What are the ranges of parasite stability among various host communities in China? Parasitol Int. 2006:55:S237-46.

11. Craig PS. Epidemiology of human alveolar echinococcosis in China. Parasitol Int. 2006:55:S221-5.

12. Xiao N, Nakao M, Qiu JM, Budke CM, Giraudoux P, Craig PS, et al. Short report: dual infection of animal hosts with different Echinococcus species in the eastern Qinghai-Tibet plateau region of China. Am J Trop Med Hyg. 2006;75:292-4.

13. Boufana B, Qiu JM, Chen XW, Budke CM, Campos-Ponced M, Craig PS. First report of Echinococcus shiquicus in dogs from eastern Qinghai-Tibet plateau region. China. Acta Trop. 2013;127:21-4

14. Giraudoux P, Raoul F, Afonso E, Ziadinov I, Yang YR, Li L, et al. Transmission ecosystems of Echinococcus multilocularis in China and Central Asia. Parasitology. 2013;140:1655-66.

15. Jiang WB, Liu N, Zhang GT, Renqing PC, Xie F, Li TY, et al. Specific detection of Echinococcus spp. from the Tibetan fox (Vulpes ferrilata) and the red fox (V. vulpes) using copro-DNA PCR analysis. Parasitol Res. 2012;111:1531-9.

16. Liu QX, Harris RB, Wang XM. Food habits of the Tibetan fox (Vulpes ferrilata) in the Kunlun Mountains, Qinghai Province. China. Mamm Biol. 2010:75:283-6.

17. Wang H, Zhao HL, Ma SM, Cao DP, Chai JJ. Investigation on infections of Echinococcus in animals in Qinghai Plateau. Endem Dis Bull. 2000;15:29-33.

18. Zhang JX, Wang $\mathrm{H}$. Epidemiology of Echinococcus in animal host species of Qinghai province. Chin J Parasitol Parasit Dis. 2007;25:350-2.

19. Raoul F, Quéré JP, Rieffel D, Bernard N, Takahashi K, Scheifler R, et al. Distribution of small mammals in a pastoral landscape of the Tibetan plateaus (Western Sichuan, China) and relationship with grazing practices. Mammalia. 2006;70:214-25

20. He JG, Qiu JM, Liu FJ, Chen XW, Liu DL, Chen WD, et al. Epidemiological survey on hydatidosis in Tibetan region of western Sichuan. II. Infection situation among domestic and wild animals. Chin J Zoonoses. 2000;16:62-5.

21. Zhao HL. Investigation on infections of alveolar hydatid in small mammals at south Qinghai Plateau. J Qingh Med Colle. 2002;23:12-4.

22. Wang ZH, Wang XM, Lu QB. Selection of land cover by the Tibetan fox Vulpes ferrilata on the eastern Tibetan Plateau, western Sichuan Province. China. Acta Theriol. 2007:52:215-23.

23. Ma B, Wang XM, Liu XQ, Wang ZH. GIS analysis of the spatial relationship between plateau burrow distribution and vegetation distributional patterns. Biodivers Sci. 2011;19:71-8.

24. Luo ZX, Chen W, Gao W. Fauna Sinica Mammalia Vol. 6 Rodentia Part II: Cricetidae. Beijing: Science Press; 2000.

25. Smith AT, Xie Y, editors. A guide to the mammals of China. Princeton: Princeton University Press; 2008. p. 55-184.

26. Nakao M, Sako Y, Yokoyama N, Fukunaga M, Ito A. Mitochondrial genetic code in cestodes. Mol Biochem Parasit. 2000;111:415-24.

27. Boufana B, Umhang G, Qiu JM, Chen XW, Lahmar S, Boué F, et al. Development of three PCR assays for the differentiation between Echinococcus shiquicus, E. granulosus (G1 genotype), and E. multilocularis DNA in the co-endemic region of Qinghai-Tibet plateau, China. Am J Trop Med Hyg. 2013;88:795-802.

28. Nakao M, Li TY, Han XM, Ma XM, Xiao N, Qiu JM, et al. Genetic polymorphisms of Echinococcus tapeworms in China as determined by mitochondrial and nuclear DNA sequences. Int J Parasitol. 2010;40:379-85.

29. Nagelkerke NJD. A note on a general definition of the coefficient of determination. Biometrika. 1991;78:691-2.

30. Burnhan KP, Anderson DR. Model selection and multimodel inference: a practical information-theoretic approach. 2nd ed. New York: Springer-Verlag; 2002.

31. Delattre P, Pascal M, LePesteur MH, Giraudoux P, Damange JP. Caractéristiques éologiques et épidémiologiques de 1'Echinococcus multilocularis au cours d'un cycle complet des populations d'un hôte intermédiaire (Microtus arvalis). Can J Zool. 1988;66:2740-50.

32. LePesteur MH, Giraudoux P, Delattre P, Damange JP, Quéré J-P. Spatiotemporal distribution of four species of cestodes in a landscape of mid-altitude mountains (Jura, France). Ann Parasitol Hum Comp. 1992;67:155-60.

33. Giraudoux P, Delattre $P$, Takahashi K, Raoul F, Quéré J-P, Craig P, et al. Transmission ecology of Echinococcus multilocularis in wildlife: what can be 
learned from comparative studies and multiscale approaches? In: Craig P, Pawlowski Z, editors. Cestode zoonoses: echinococcosis and cysticercosis: an emergent and global problem. Amsterdam: IOS Press; 2002. p. 251-66.

34. Burlet P, Deplazes $P$, Hegglin D. Age, season and spatio-temporal factors affecting the prevalence of Echinococcus multilocularis and Taenia taeniaeformis in Arvicola terrestris. Parasit Vectors. 2011:4:6.

35. Morris P. A review of mammalian age determination methods. Mammal Rev. 1972:2:69-104.

36. Burlet $P$, Deplazes $P$, Hegglin $D$. Efficient age determination: how freezing affects eye lens weight of the small rodent species Arvicola terrestris. Eur $J$ Wildlife Res. 2010;56:685-8.

37. Hall T. BioEdit: An important software for molecular biology. GERF Bull Biosci. 2011;2:60-1.

38. Larkin MA, Blackshields G, Brown NP, Chenna R, Mcgettigan PA, Mcwilliam $H$, et al. Clustal W and Clustal X version 2.0. Bioinformatics. 2007:23:2947-8.

39. Librado P, Rozas J. DnaSP v5: a software for comprehensive analysis of DNA polymorphism data. Bioinformatics. 2009;25:1451-2.

40. Xia XH. DAMBE5: A comprehensive software package for data analysis in molecular biology and evolution. Mol Biol Evo. 2013;30:1720-8.

41. Darriba D, Taboada GL, Doallo R, Posada D. jModelTest 2: more models, new heuristics and parallel computing. Nat Methods. 2012;9:772-2.

42. Ronquist F, Huelsenbeck JP. MrBayes 3: Bayesian phylogenetic inference under mixed models. Bioinformatics. 2003;19:1572-4.

43. Zhang RZ, Jin SK, Quan GQ, Li SH, Ye ZY, Wang FG, et al. Distribution of mammalian species in China. Beijing: China Forestry Publishing House; 1997. p. 240-1.

44. Jiang ZG, Ma Y, Wu Y, Wang YX, Zhou KY, Liu SY, et al. China's mammal diversity and geographic distribution. Beijing: Science Press; 2015. p. 253373.

45. Hu QC, Wang YX. Sichuan fauna economica Vol. 2. Chengdu: Sichuan Science and Technology Press; 1984.

46. Wang YZ. Comparison of the mammal community composition based on surveys conducted in 1959 and 1987 in Shiqu County. In: Xia WP, Zhang J, editors. The successional changes of mammals in China under the influences of human activities. Beijing: China Science and Technology Press; 1993. p. 155-8.

47. Wang LM, Yang K, Xie F, Tan WM, Li GJ, Wu CX, et al. Surveillance result of natural foci of Microtus fuscus in Sichuan Province from 2000 to 2012. Chin J Control Endem Dis. 2013;28:335-7.

48. Qi T, Yang K, Wang LM, Duan YJ, Xie F, Yang J, et al. Epidemiology in plague foci of Shiqu County, China, 2001-2013. Chin J Zoonoses. 2015;31: 485-8.

49. Zhao L, Zhou S, Yan DH, Zhang TY, Tang ZY, Su J. Developing trend and controlling countermeasures of pests and mice of Sichuan grassland in 2015. Pratac Anim Husb. 2015;220:49-53.

50. Zhao L, Yan DH, Zhang XX, Zhou S. Actuality and control technology of prairie rodent pests in Sichuan. Pratac Anim Husb. 2015;221:1-7.

51. Giraudoux P, Raoul F, Pleydell D, Li TY, Han XM, Qiu JM, et al. Drivers of Echinococcus multilocularis transmission in China: small mammal diversity, landscape or climate? PLoS Negl Trop Dis. 2013;7:e2045.

52. Wang H, Zhang JX, Schantz PM, Ito A, Craig PS. Epidemiologic survey and analysis on echinococcosis in humans and animals from 1995 to 2005 in Qinghai province. Chin J Zoonoses. 2006;22:1129-34.

53. He DL, Wang H. A report on the epidemiological evaluation of hydatid disease in Zeku County, Qinghai Province. Endem Dis Bull. 2001;16:36-8.

54. Han XM, Wang H, Ma X, Cai HX, Liu YF, Wei BH, et al. Epidemiological survey on echinococcosis in Darlag County of Qinghai Province. Chin J Parasit Dis. 2009:27:22-6.

55. Gandon S. Evolution of multihost parasites. Evolution. 2004;58:455-69.

56. Wang Q, Raoul F, Budke C, Craig PS, Xiao YF, Vuitton DA, et al. Grass height and transmission ecology of Echinococcus multilocularis in Tibetan communities. China. Chin Med J. 2010;123:61-7.

57. Smith AT, Zahler P, Hinds AA. Ineffective and unsustainable poisoning of native small mammals in temperate Asia: aclassic case of the science-policy divide. In: McNeely JA, McCarthy TM, Smith A, Olsvig-Whittaker L, Wikramanayake ED, editors. Conservation biology in Asia. Kathmandu: Society for Conservation Biology Asia Section and Resources Himalaya; 2006. p. 285-93.

58. Thompson RCA, Mcmanus DP. Aetiology: parasites and life-cycles. In: Eckert J, Gemmell MA, Meslin FX, Pawlowski ZS, editors. WHO/OIE manual on echinococcosis in humans and animals: A public health problem of global concern. Paris: World Health Organization; 2001. p. 1-17.
59. Saarma U, Jõgisalu I, Moks E, Varcasia A, Lavikainen A, Oksanen A, et al. A novel phylogeny for the genus Echinococcus, based on nuclear data, challenges relationships based on mitochondrial evidence. Parasitology. 2009:136:317-28.

60. Knapp J, Nakao M, Yanagida T, Okamoto M, Saarma U, Lavikainen A, et al. Phylogenetic relationships within Echinococcus and Taenia tapeworms (Cestoda: Taeniidae): an inference from nuclear protein-coding genes. Mol Phylogenet Evol. 2011;61:628-38.

61. Trachsel D, Deplazes P, Mathis A. Identification of taeniid eggs in the faeces from carnivores bsed on multiplex PCR using targets in mitochondrial DNA. Parasitology. 2007;134:911-20.

\section{Ready to submit your research? Choose BMC and benefit from:}

- fast, convenient online submission

- thorough peer review by experienced researchers in your field

- rapid publication on acceptance

- support for research data, including large and complex data types

- gold Open Access which fosters wider collaboration and increased citations

- maximum visibility for your research: over $100 \mathrm{M}$ website views per year

At BMC, research is always in progress.

Learn more biomedcentral.com/submissions 